\title{
DOCUMENTATION OF TRADITIONAL HOUSING IN MAYANGNA COMMUNITIES. BOSAWÁS BIOSPHERE RESERVE, NICARAGUA
}

\author{
G. Cimadomo ${ }^{1, *}$, N. González Meixuero ${ }^{2}$, J.L. Jamauca ${ }^{2}$, C. Castaño Gil ${ }^{2}$, M. Martín Sánchez ${ }^{3}$ \\ ${ }^{1}$ Departamento Arte y Arquitectura, Universidad de Málaga, Spain - cimadomo@uma.es \\ ${ }^{2}$ ETS Arquitectura, Universidad de Málaga, Spain - (nathaliameixueiro, chelo.jamauca, carloscastanoarch)@gmail.com \\ ${ }^{3}$ ETS Arquitectura, Universidad Politécnica de Valencia, Spain - martamartinsanchez96@gmail.com
}

Comission II - WG II/8

KEY WORDS: Vernacular dwelling, Mayangna, Documentation, North Caribbean Coast Autonomous Region, Nicaragua

\begin{abstract}
:
The Mayangna ethnic community populate the UNESCO Bosawás Biosphere Reserve in the north of Nicaragua, in the North Caribbean Coast Autonomous Region. During the volunteer program developed by the School of Architecture at the University of Malaga, Spain in the summer of 2019, the architecture of a traditional Mayangna house in Santa María (Bonanza municipal term) was documented. Documentation and digital reconstruction of this typology is still inadequate and this is considered a crucial task given that many of these traditional buildings are at risk of disappearing, as the comparison with more recent buildings in Sakalwas (Bonanza) shows. The paper describes, focusing on a typological and construction analysis, the original houses and the domestic culture of this community, characterized by the use of pressed bamboo for the external walls and Suita palm leaves for the roofs. Other characteristics are the lack of internal distribution and the use of piles to elevate the single roof from the ground. A slow process of transformation has been detected, leading to increased environmental costs and less effective solutions for combating tropical climatology and heavy raining periods. Finally, we discuss how the active protection of the Biosphere Reserve should be compatible with the preservation of traditional houses, for a more socially and environmentally sustainable future.
\end{abstract}

\section{INTRODUCTION}

The Higher Technical School of Architecture of the University of Malaga has been developing a line of research on vernacular architecture documentation for several years, focusing especially on southern Morocco and lately on Nicaragua (Cimadomo, 2008, 2018; Cimadomo et al., 2012; López Osorio et al., 2012).

Through the volunteer program organized by the University in collaboration with the Andalusian Agency for International Development Cooperation, four undergraduate and master students of the School of Architecture have had the opportunity during the summer of 2019 to develop a two-month stay in Bonanza, in the North Caribbean Coast Autonomous Region (RACCN). Their duties were focused on technical support for the design and planning activities of the Office of Urban and Development Planning (Oficina del Plan de Ordenación y Desarrollo Urbano, PODU).

The fieldwork developed led to the recognition of a vernacular typology typical to the local Mayangna community, which provides a unique opportunity to develop a survey of the domestic buildings in this region since they are not sufficiently documented by the international scientific community. The main objective, summarized in the compilation of Mayangna domestic reality and in the documentation of its residential buildings, is to increase the possibilities for a better understanding of the existing cultural diversity, as well as a 'performative interpretation' that allows the recognition of ancestral community values, and can consolidate an increasingly eroded cultural identity (Silberman, 2012).
The justification for undertaking this work is the transformative and alterative process that the community is undergoing due to the contamination by other cultures, especially based on neoliberal globalization policies. This project is the first step towards establishing risk assessment policies related to domestic traditions, in the framework of strengthening the Mayangna community led by local authorities.

This documentation process takes into account the concept of Heritage BIM (H-BIM), to include those artistic, historical and constructive aspects linked to the local constructive tradition (Cimadomo, 2016; López et al., 2018). For the correct transmission of the values linked to these vernacular buildings, it is necessary to propose the best forms of survey taking into account the limitations existing in the context of the project and the environment in which we operate. First, the simplicity of the constructions suggests that high detail or virtual reconstruction (laser scanner, point clouds) are not the most appropriate tools, since the main value lies in the construction and application of material solutions used in a simple way in different buildings. Of course low cost and user-friendly survey with DSLR could be easily developed, but without an existing relationship with the dwellers, it could be considered as predatory and an intrusion to their domestic world. A traditional survey allows an immersion in the constructive logic of the house and its use, with the participation of the home owners who contribute their knowledge and form a necessary part of the work: these insights would be lost using other digital procedures (Nichols et al., 2017). This approach offers a deeper understanding to the different heritage dimensions, with special attention to the social component and cultural identity of this community. Another long term aim of this survey is to promote cultural authenticity in the construction

* Corresponding author 
process, with a focus on the most characteristic elements of these homes which experiment a continuous process of replacement by industrialized processes. Keeping this practice alive would allow the repair of older homes, the use of sustainable techniques in new buildings, as well as the protection of the values of the Mayangna culture. In addition, there are the associated socioeconomic development possibilities linked to cultural and environmental heritage meant as an engine of new productive dynamics.

\section{MAYANGNA CULTURE}

The Sumu-Mayangna culture is distributed between northwestern Nicaragua and southern Honduras. Apart few documents from the colonial era, the first descriptions about this ethnic group came from travelers and historians of the 19th century. Its history, on the other hand, has been transmitted mostly by oral tradition. It is important to note that prior to colonization, Mayangna history was transmitted non-linearly, where what stood out was the teaching or moral of the story, rather than the fact itself. This is an aspect that has been greatly affected by Spanish colonialism first, and later, English.

The Bio-Protocol of free consultation and consent of the Mayangna people generated by the International Union for the Conservation of Nature (IUCN) (AAVV, 2014) divides its worldview into three areas: spiritual, moral and cultural, the last one being of special interest in this work because of its focus on respect for natural resources. The Mayangna have always been aware of their surroundings and the relationship with nature has been of special importance to them. They know their territory and their natural resources, and profess the harmonious order between nature and man. The term 'ecological balance', a paradigm of exceptional relevance that is still difficult to implement in contemporary society, has been part of the daily life of this ethnic group since the dawn of time.

The Bosawás Biosphere Reserve (a name derived from the initials of the geographical references of the area: BO: Bocay River, SA: Cerro Saslaya, and WAS: Waspuk River) is located northeast of Nicaragua, and is the place where at present $66 \%$ of the Mayangna population lives (Figure 1). It is an area protected by UNESCO since 1991, and is listed as the largest reserve in Central America. For indigenous peoples, the reserve has historically been the provider of the necessary resources for their subsistence: $94 \%$ of the inhabitants take advantage of the forest for self-consumption and view their land as part of their indigenous identity. In other words, its natural environment is the root of its biological, social and spiritual survival, although this relationship is attenuated by the integration into the global dynamics that slowly reached the region.

The factors that put pressure on the forest in the RACCN are forest fires, the advance of the agricultural frontier, illegal logging (more than double the legal extraction), land tenure linked to the presence of "third parties" or "settlers" (mostly non-indigenous people from the Pacific and northern Nicaragua who are occupying indigenous territories and transferring unsustainable practices according to land use and the area's own resources), pests, mining concessions, inadequate forestry strategies and policies, disorderly exploitation, poor inter-institutional coordination, lack of consensus and citizen participation mechanisms, inadequate instruments for resource regulation and accelerated and irrational approval of forest exploitation plans (AAVV, 2014, p. 104).
One of the current problems of the community is the invasion of their territories by settlers attracted by the natural resources that exist in the region. According to the Bio-Protocol of Consultation, since 2010 colonization has accelerated, with new settlers occupying the lands of the natives and taking away their resources. As a result, the Mayangna are being displaced from the banks of the rivers to the headwaters of the basins, effectively reducing the geographical area in which they can live and at the same time setting limitations to the use of water resources for transport, fishing and hunting. In an attempt to limit deforestation in the area, a protocol prohibiting certain activities, including the use of wood for the building, has been implemented. Ultimately, these rules, as we shall see later, have a negative impact on the local population.

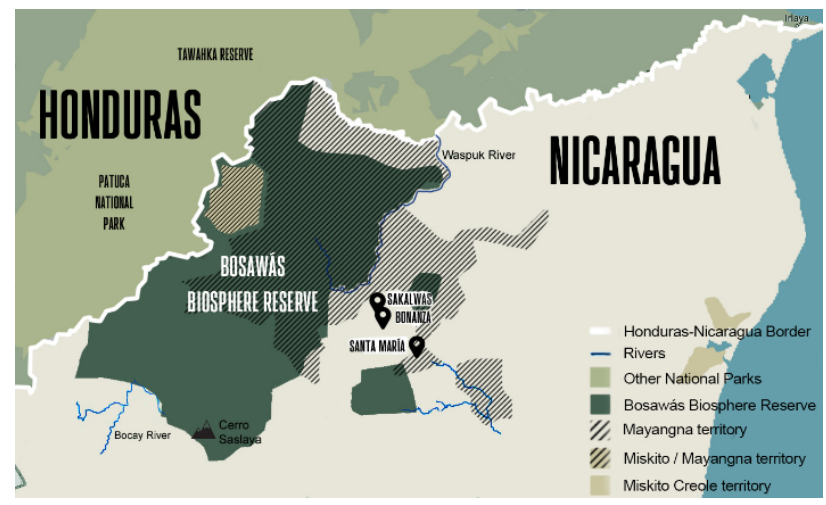

Figure 1. Location map of the Bosawás Biosphere Reserve and Mayangna territories in the North Caribbean Coast Autonomous Region, Nicaragua.

\section{DOMESTIC CULTURE}

The turning point that drove the first transformations to indigenous housing can be found in the Moravian evangelization stage that begins in the mid-nineteenth century (Bataillon and Galindo Juárez, 2007). "It was not because of the influence of the missionaries that the Sumu changed the traditional form of housing that they had maintained for centuries and that had proved to be adequate. Houses without side walls have become scarce." (Houwald, 2003, p. 319). The engineer Bruno Mierisch, who visited the area in 1891, described the houses as "extremely simple, four posts and a palm leaf roof on top; that's usually it" (Houwald, 2003, p. 328). In the same way, missionary K. Müller explained indigenous housing as "The houses of the Indians formerly were no houses at all in the sense that civilized people understood this word. They were constructed of about four to six posts of the hardest wood available, dug into the ground, and a roof of either Bapta Palm leaf of Scomfra reeds, or Attack leaves" (Houwald, 2003, p. 330). The main transformations related to housing are the lifting of the floor with respect to the land carried out on pillars and the diffusion of the perimeter enclosures of the houses to guarantee greater privacy for the families. These transformations, however, are not simply originated by an imposition by the evangelizers for a more 'civilized' way of life or according to colonialist moral criteria. As an example, the evangelizing movement was key in supporting the consolidation of an indigenous identity opposed to Nicaragua's attempts to impose a national identity, creating mutual interests for cohabitation. Once converted, the indigenous people could not continue with their traditional way of life, having acquired new needs and opened up to cultural pollution (Bataillon, Galindo Juárez, 2007, p. 58). 
An exhaustive description of the domestic habits of the Mayangna culture can be reconstructed through the work of the ethnologist Eduard Conzemius, which was carried out at the beginning of the 20th century and have not changed substantially over the years, as was observed during the field work (Conzemius, 1932, 2017).

The bed was a carpet made of tree barks, bijagua leaves and deer hides on the ground: the Sumu called it 'Takal'. Subsequently, a mat of split reeds supported by poles and raised one meter above the ground was found. The layers of crushed tree barks served as mattresses and blankets. They also used the mosquito nets, an invention that came from one of the many foreigners' trips to the area. Some older descriptions also present a kind of simple upper floor ('tent') made with tables that served as a simple sleeping area, although this attic seems to have been lost with the transformation from collective grouped dwellings to scattered single houses. The use of the same floor of the house as a place to sleep, described by some travellers (Houwald, 2003) was observed during the field work, as many of the houses surveyed had no mattresses or similar furnitures. The census of the Pan American Health Organization conducted between December 2003 and February 2004 highlights the presence of 2.9 mattresses per home in Sakalwas, confirming this habit but also demonstrating a possible slow change in this trend (Davis Wilson, 2004, p. 67). Household goods and clothing were very scarce, and they still are, despite having adapted their way of dressing to Western culture. These are often located in simple shelves or hung from the ceiling, as in the case of fishing and hunting tools, bottles filled with achiote for painting their bodies, hair oil and small pumpkins with pellets for hunting (Figure 2). "And yet as the Christian community life develops, it becomes evident that the very primitive clothing of heathen times, must be replaced by neat and becoming garments. It is also soon learned that a truly Christian family life cannot be carried on in the open shelters of the olden days, for a Christian family needs a house, which is a home, and that cannot be unless the house has walls and is divided into more than one room". (Mueller 1932; cited in Bataillón, Galindo, 2007, p.58).

Another notable element was the stove used for cooking, it was made up of three wooden logs placed in a ' $\mathrm{Y}$ ' shape, leaving a space in the centre for the fire. The smoke, which escaped slowly from the house through the roof of palm leaves, functioned as a repellant for mosquitoes. At present, this system is being replaced by metal grills fed with firewood placed close to a window (Figure 3). It is evident, as marked in the Charter of the Built Vernacular Heritage (ICOMOS, 1999, p. 2) that the heritage is not limited to the material elements, but to its relevance to the community.

\section{TRADITIONAL MAYANGNA HOUSE CONSTRUCTION AND ITS EVOLUTION}

During the volunteer project funded by the University of Malaga, Spain and the Andalusian Agency for International Development Cooperation, it was possible to visit the Santa María and Sakalwas villages, near the city of Bonanza, capital of the province located in the mining triangle of the region. Both locations are inhabited exclusively by members of the Mayangna community, which allowed us to observe their characteristic way of life, reflected in the spatial organization of the territory as well as in their homes.

Santa María is located 19 kilometres east of Bonanza, half an hour's walk from the main road network that crosses the region. In this settlement two traditional houses have been found, which maintain all their elements of the ancestral Mayangna culture. Maria Yoilen's house, built by members of the community following traditional methods transmitted from generation to

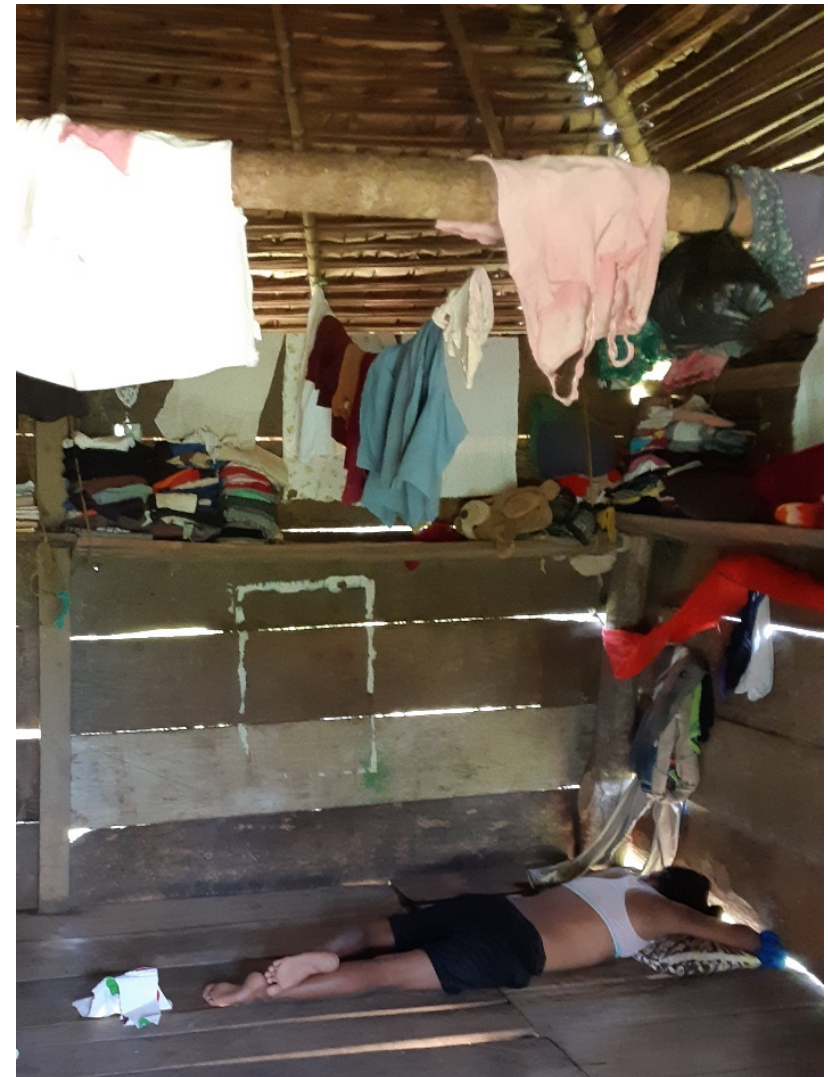

Figure 2. Inner view of a Mayangna dwelling in Santa María, Bonanza (Nathalia González).

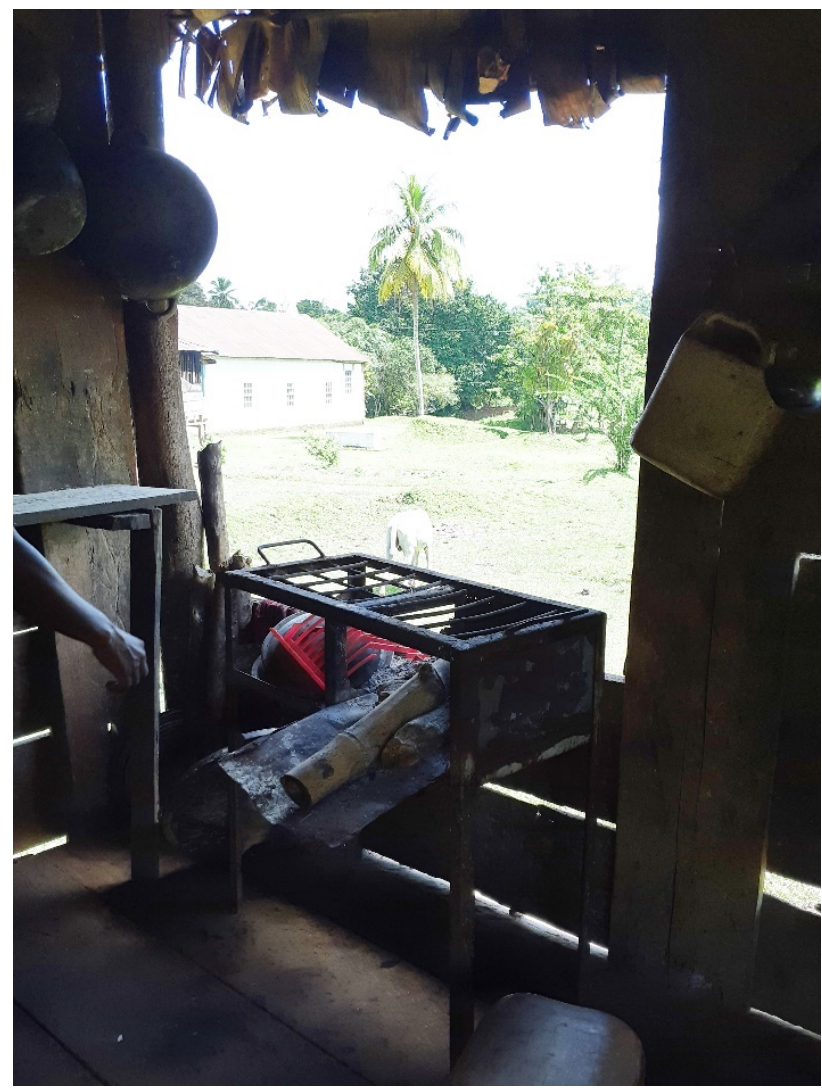

Figure 3. Inner view of a Mayangna dwelling in Santa María, Bonanza (Nathalia González). 
generation, was analysed. This house was chosen because it is the only one that still maintains all the traditional construction characteristics described by 19th century travellers and outlined in Chapter 3, in addition to present two different solutions of vertical enclosures.

Sakalwas $(65,4$ Ha.) is located about four kilometres north of Bonanza, and is a more accessible and better documented settlement due to its proximity to the regional capital and the completion of population censuses in 2004 and 2019, the basis of the future Urban and Development Plan. It has 121 families distributed in 101 homes $(44,51 \%$ of the houses are inhabited by a single family), resulting in very high population densities with up to 30 people from five different families living in the same house of approximately 70 square meters. Census statistics of the Pan American Health Organization reflect that Sakalwas homes have an average surface area of 40 sq. meters, mostly made of wooden plank walls and zinc roofs $(90.9 \%)$. They have an average of 2.45 rooms and an average of 7.82 people live in them (Davis Wilson, 2004, p. 67).

These statistics reflect the scarce importance that indigenous culture traditionally assigns to housing, the most important being the connection with the land and the activities that take place there. There is no urban logic in the spatial organization of the community, the houses are randomly distributed in the territory and isolated as much as possible from each other. In Sakalwas all the houses that are maintained according to the traditional typology have been adapted to the use of industrial materials, a clear demonstration of the risk of loss of the values related to the original construction traditions.

Maria Yolen's house was inhabited by eight people and was divided into two modules of approximately square dimensions, the first was 4 meters by 3.80 meters, and the second 3.5 meters by 3 meters (Figure 4). The floor was raised approximately 1 meter above the ground which is the common practice today ('tambo' solution). In addition to separating the soil from the ground thus creating better ventilation in the rooms, this practice protects the building from moisture, floods or water stagnations, and provides a shaded area in which domestic animals find refuge. In addition to these practical functions, there are other equally important symbolic ones. Local cosmogonies consider the construction on stilts a form of respect for Liwa, owner of the waters, separating the house from water and protecting the inhabitants from her punishments (Cruz Ramírez, León Hernández, 2017). Access is made through a wooden staircase directly to a porch that occupies a quarter of the first volume which functions as a bedroom. The second volume, designated for cooking, is accessed through an extension of the porch, at the centre of its longest side. The rooms did not have interior partitions, nor any furniture except a grill for cooking and a shelf for the storage of personal belongings. The rest of kitchen tools and other belongings hung directly on the perimeter walls. Although it was not observed during the field work, the bedrooms are now increasingly divided by curtains during the night, creating a higher level of privacy for its inhabitants.

There is a common pattern in the constructions, with each volume being built independently. Four posts are placed on the ground corresponding to the corners of the volume, which together with other intermediate posts of square section make up a matrix of nine supports for the larger volume and seven for the smaller one. These serve as support for the structure of the wood slab and the bridge, composed of two orders of horizontal stringers placed at $90^{\circ}$ with the floor boards directly nailed on top (Figure 5). The corner posts reach the crowning height of the vertical partitions along with other elements distributed above the slab. All of them hold a second horizontal stiffening perimeter structure supporting the roof and the envelope. A beam that crosses the modules in half gives stabilization to the whole structure. All the joints made in a simple way, and nails are used only when strictly necessary (Figure 6).
In this house we found two different treatment for the walls of the volumes. The kitchen was built with rough wooden planks placed horizontally and nailed to the vertical elements. The bedroom, however, had an enclosure of rammed bamboo panels (Bambusa sp.), the traditional historical solution that is less and less common today. This building technique is achieved by cutting the bamboo stem in half and then tamping it until leaving it as a plain surface that configures panels approximately 2 meters high by 0.60 meters wide.

These panels are fixed to bamboo stiffeners placed at the upper and lower ends of the enclosure and are attached to these and to the main structure of wooden logs with vines and nails. Bamboo is an abundant material and this procedure offers a thin and porous envelope that allows the constant renewal of the air, creating very ventilated rooms suitable for the local climate.

The laboriousness of its preparation is the main justification for its replacement by wooden boards, which are easier to prepare and faster to place, directly nailed to the vertical posts. Currently, the latter is the most common solution.

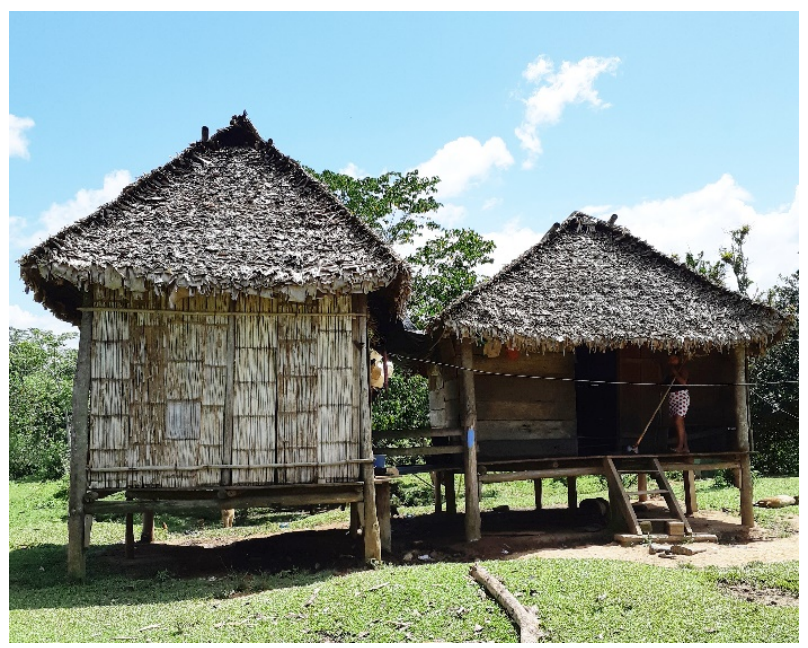

Figure 4. Panoramic view of María Yolen's house in Santa María, Bonanza (Nathalia González).

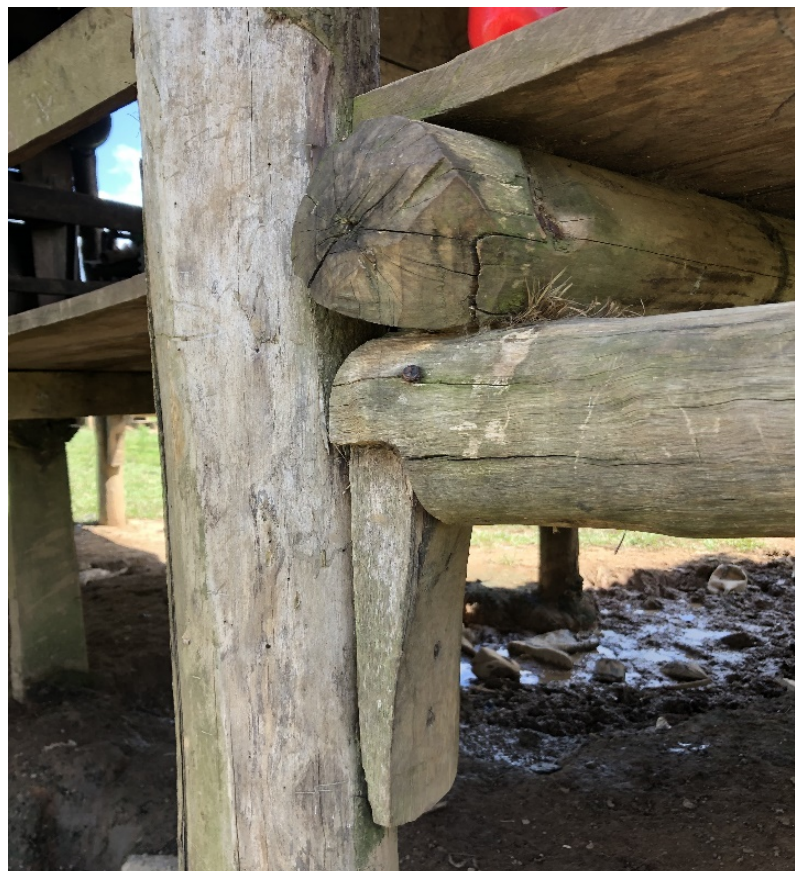

Figure 5. Detail of the structure of the main slab. Santa María, Bonanza (Nathalia González). 

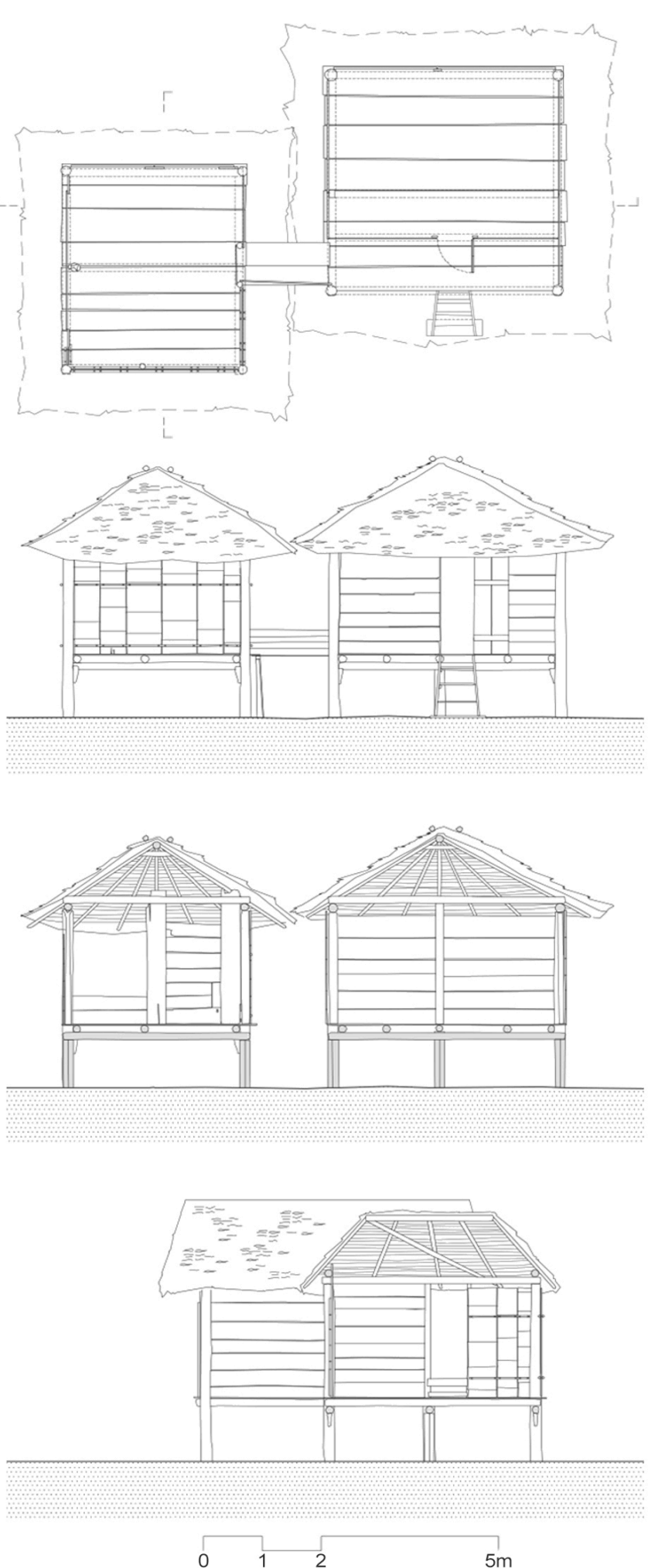

Figure 6. Plan, main façade and cross sections of the surveyed house in Santa María, Bonanza.

The laboriousness of its preparation is the main justification for its replacement by wooden boards, which are easier to collect and faster to place, directly nailed to the vertical posts.

Currently, the latter is the most common solution.
The most interesting constructive element of this house is its roof made of Suita leaves ('Calyptrogyne sarapiquensis' or 'Geonoma ghiesbreghtiana') (Figure 7). Each volume is covered by a hip roof composed of two trapezoidal slopes corresponding to the larger sides that rest on a ridge board of relevant section, and two smaller triangular hip ends, leaving two upper triangles open for ventilation. The roof has eaves of about 0.80 meters in all directions. The support structure is light, and configured as follows: the hip ends have up to seven rafters per side that converge, supporting the ridge board. The larger slopes have a smaller number of rafters (in this case three), joined by another bamboo element positioned diagonally, to increase stability and facilitate placing of the previously built-on-the-ground slope (Figure 8). On the outer side of the roof and at the height of the ventilation triangular openings, there are two bamboo stringers parallel to the ridge. These are joined to the rest of the structure by wooden elements placed inside, allowing greater resistance and stability to wind pressure. The leaves of Suita palm are placed by hand directly above this structure, traditionally by the women of the family.

As indicated in the previous section, this cover solution has become almost completely extinct, the inhabitants say that it is difficult to maintain, and it is no longer easy to find suitable leaves, nor people skilled enough to perform this work correctly. At present, the most common solution for covering homes is the use of zinc sheet ceilings, easily available on the market although at a higher cost. The zinc roof, unlike the one made with Suita leaves, does not regulate the interior temperature, amplifies the heat and cold at night when used directly on the main structure, and generates annoying noises during torrential rains.

\section{CONCLUSIONS AND FUTURE RESEARCH}

The house surveyed did not differ much from the descriptions of nineteenth-century travellers. Apparently, these houses followed a specific constructive pattern and order. In the field work, a similar house, the house of Mr. Pedro Taylor (Figure 9), that closely follows traditional patterns was identified. The house is composed of two square modules raised above the ground without any physical connection, in contrast with the surveyed one. The element that draws the attention of this house is the staircase, a notched palm trunk, similar to the ones described by Houwald for early Mayangna houses at the beginning of the 20th century. Generally, the houses observed during the field work are configured by two to three simple volumes connected with a bridge or just close one to the other, like the house surveyed. There are no inner partitions, the relation of openings is generally low, and the 'tombo' solution with elevated floors is the more common. The porch is a common feature to all houses.

The materials and traditional processes here described, adapted to the climatic and cultural conditions of the region are being replaced by faster and easier-to-place products, and traditional solutions like the one described in this paper are more difficult to find. Also if they require less maintenance, these new materials deepen the participation of the community in a capitalist system that requires economic exchange for any transaction.

In Sakalwás, but also in Santa María, it is today common to build with metal roofing sheets, which replace Suita leafs systems, and with industrial wooden boards, replacing bamboo walls. The use of new materials is indirectly transforming the shape of the houses, for example with gable roofs or mono-pitched roofs (Figure 10). In short, the substitutions carried out in the housing typology make it a less comfortable place than the traditional one, with higher costs derived from the acquisition of construction materials compared to the use of the material 


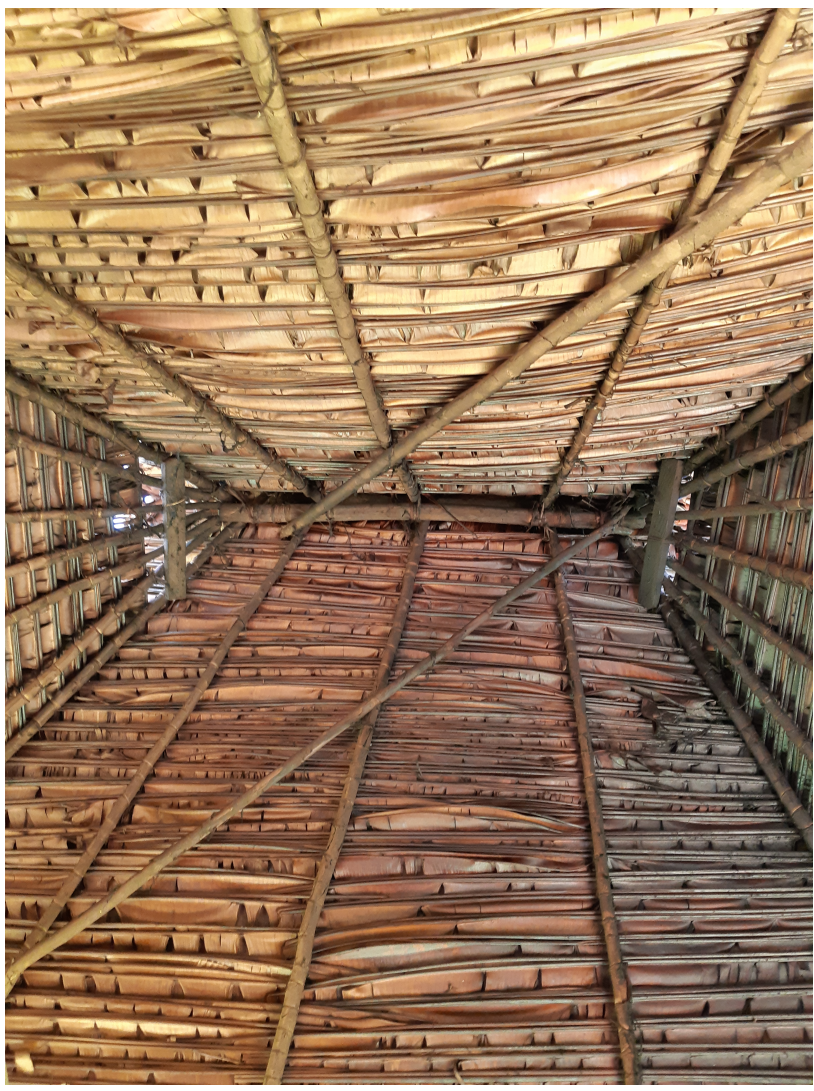

Figure 7. Bottom-up view of the inner roof made with Suita leafs. Santa María, Bonanza (Nathalia González).

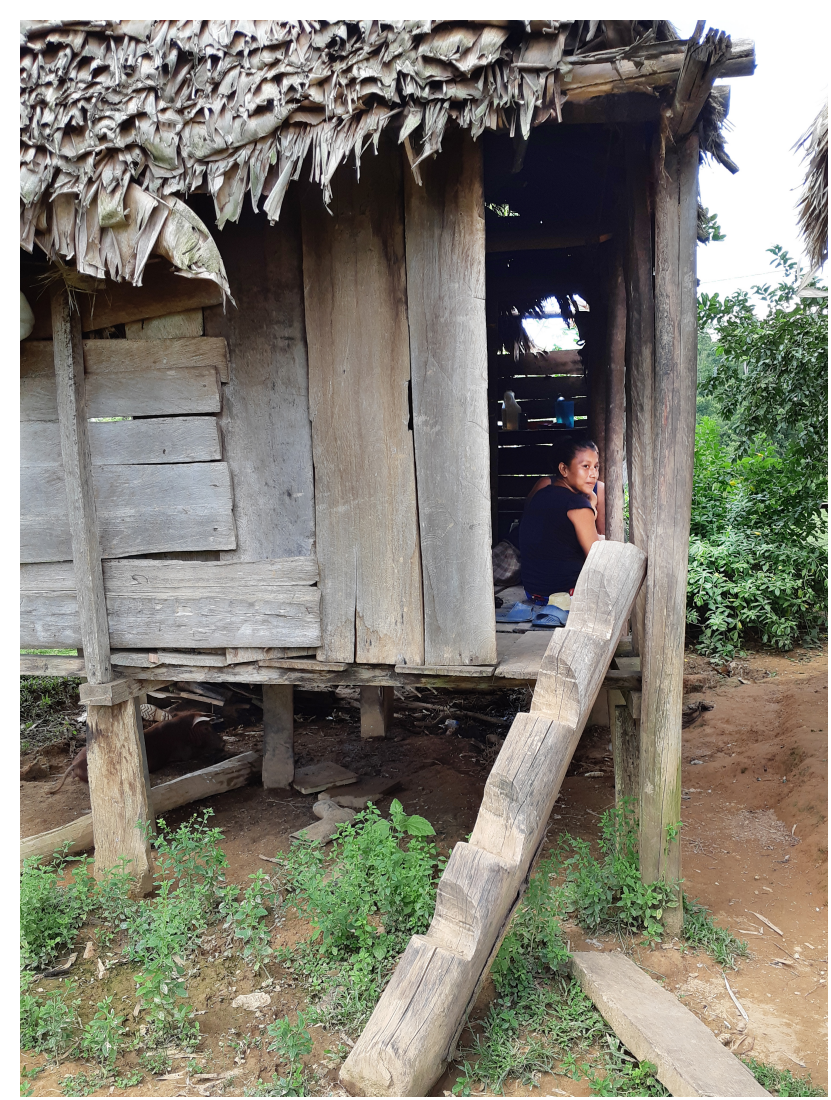

Figure 9. View of Pedro Taylor's house in Santa María, Bonanza (Nathalia González).

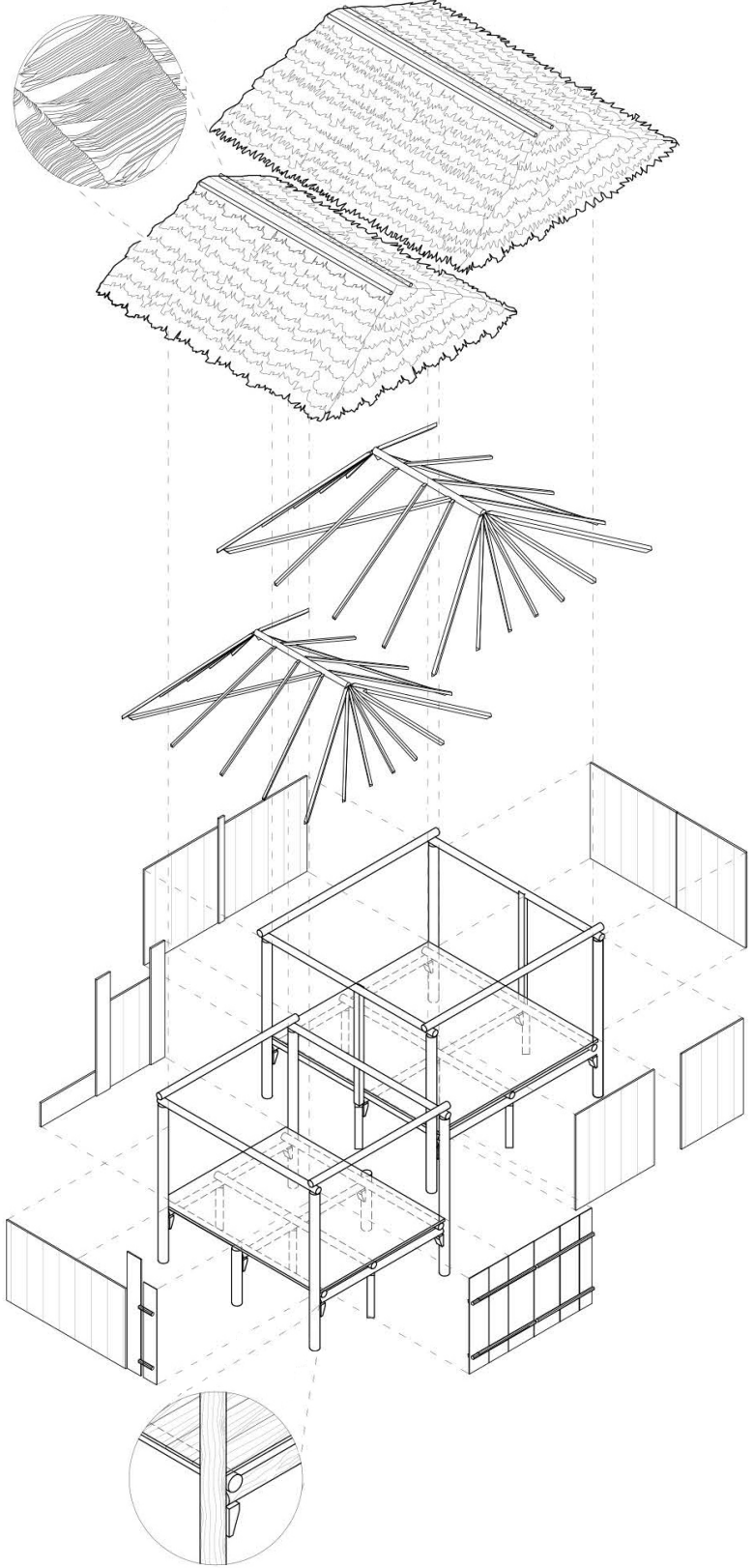

Figure 8. Isometric exploded view of Maria Yoilen's house. Santa María, Bonanza.

offered by nature itself, and the consequent environmental derived costs. It is of great importance to recognize how the prohibitions on the use of wood in the area of the biosphere reserve, although made to protect the community from indiscriminate logging, causes a limitation of the rights of the Mayangna population in maintaining their traditional housing construction systems. These existing prohibitions with respect to the felling of tree species related to the Mayangna culture ought to be modified; this would help to keep the traditions of this community alive.

In the future, the research group will work on developing a better understanding of the variables used through the visit of other Mayangna communities, as well as documenting the fabrication processes of the bamboo panels and the Suita's roofs. Thanks to a better planning of the field trip, 3D recording and basic imagebased modelling are expected, with attention to the difficulty of modelling the most natural elements such as bamboo and Suita sheets (Figure 10). 
Finally, measurements of the thermo-acoustic conditions of the houses should be made possible, to compare the traditional solution with the ongoing evolution, as a way of justifying the goodness of the ancestral solutions and their possible reaffirmation about less respectful habits with the Mayangna tradition.

All these activities have the ultimate goal of promoting better ways of managing cultural and natural heritage in connectivity, that would benefit the sustainable development needs of this society. This can only be made possible through the promotion of people centred approaches to conservation of nature and culture.

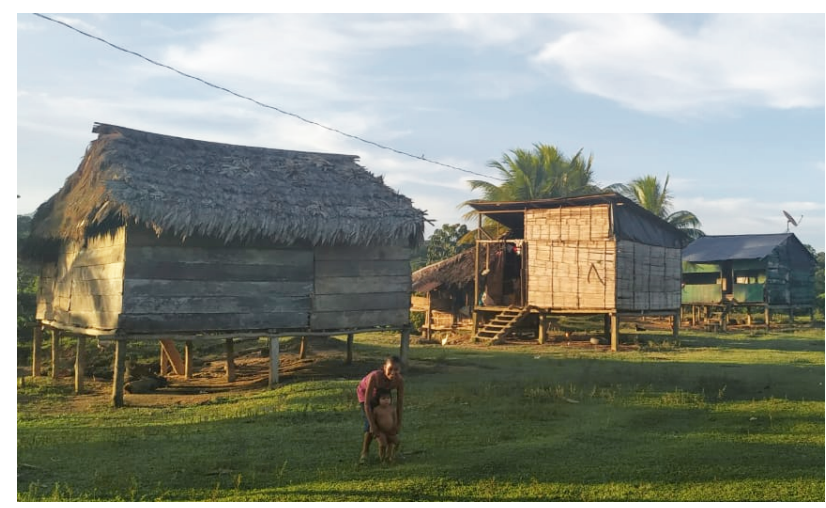

Figure 10. View of a traditional and transformed houses near Santa María, Bonanza. (Lic. Milena Martinez).

\section{AKNOWLEDGEMENTS}

This work has been possible thanks to the University Volunteering Program in International Cooperation for Development Exp. 2017SEC004 funded by the Universidad de Málaga and Agencia Andaluza de Cooperación Internacional al Desarrollo.

We are also thankful to all the staff at the Oficina del Plan de Ordenamiento y Desarrollo Urbano at the Bonanza local authority for their help, and to the Mayangna community to open their doors to us.

Tinki

\section{REFERENCES}

AAVV, 2014. Bio-protocolo de consulta y consentimiento libre, previo e informado (CLPI) del Pueblo Mayangna Sauni Arungka, Territorio Matumbak Región Autónoma de la Costa Carbie Norte (RACCN), Nicaragua. IUCN Regional Office for Mexico, Central America and the Caribbean, San José de Costa Rica.

Bataillon, G., Galindo Juárez, V., 2007. Protestantismo moravo y establecimiento de nuevos habitus entre los misquitos nicaragüenses (1848-2000). Estud. Sociológicos 25, 41-68.

Cimadomo, G., 2008. La intervención patrimonial en Nicaragua: El éxito del Catálogo de Bienes Patrimoniales de la ciudad de Granada., in: Congreso Internacional de Rehabilitación Del Patrimonio Arquitectónico y Edificación. Patrimonio Cultural e Innovación. Libro de Actas. Centro Internacional de Conservación del Patrimonio, Gran Canaria-Sevilla, pp. 259264.
Cimadomo, G., 2016. Patrimonio como valor. Nuevas herramientas para la participación de las comunidades en la puesta en valor del patrimonio cultural. PH Boletín del Inst. Andaluz Patrim. Histórico 212-214.

Cimadomo, G., 2018. Architecture, Heritage, and Tourism in Nicaragua and Morocco, in: Salvatore, C.L. (Ed.), Cultural Heritage Care and Management: Theory and Practice. Rowman \& Littlefields, London.

Cimadomo, G., Simón Montesinos, J.A., Vacas Álvarez, A., 2012. Cataloging and typological study of Mgoun Valley's traditional fortified architecture, Morocco., in: Mileto, C., Vegas, F., Cristini, V. (Eds.), Rammed Earth Conservation. CRC Press/Balkema, Boca Raton, pp. 493-498.

Conzemius, E., 1932. Ethnographical survey of the Miskito and Sumu indians of Honduras and Nicaragua. Bur. Am. Ethnol. Bull. $1-191$.

Conzemius, E., 2017. Estudios etnológicos y lingüísticos sobre el Caribe centroamericano. Academia de Geografía e Historia de Nicaragua, Managua.

Cruz Ramírez, L.C., León Hernández, R.A., 2017. Vivienda vernácula palafítica mayangna y miskitu de Nicaragua. Arquitectura $+2,23-31$.

Davis Wilson, T., 2004. Estudio comparativo entre los pueblos indígenas mayangna y miskitu y la comunidad etnica creole en los municipios de Puerto Cabezas y Bonanza.

Houwald, G. von, 2003. Mayangna. Apuntes sobre la historia de los ingígenas Sumu en Centroamérica. Fundación Vida, Managua.

ICOMOS, 1999. Charter on the Built Vernacular Heritage.

López, F., Lerones, P., Llamas, J., Gómez-García-Bermejo, J., Zalama, E., 2018. A Review of Heritage Building Information Modeling (H-BIM). Multimodal Technol. Interact. 2, 21. https://doi.org/10.3390/mti2020021

López Osorio, J.M., Montiel Lozano, A., Martín Codes, Ú., 2012. Rammed-earth construction in Southern Morocco. A reappraisal of technology, in: Mileto, C., Vegas, F., Cristini, V. (Eds.), Rammed Earth Conservation. CRC Press/Balkema, Boca Raton, pp. 169-174.

Nichols, J., Fong, D., Avey, S., 2017. Multi-modal archiving: reenvisioning Acehnese built cultural heritage, in: Greenop, K., Landorf, C. (Eds.), Digital Cultural Heritage: Future Visions. Brisbane, p. 22.

Silberman, N.A., 2012. Heritage interpretation and human rights: documenting diversity, expressing identity, or establishing universal principles? Int. J. Herit. Stud. 18, 245-256. https://doi.org/10.1080/13527258.2012.643910 